Thorax (1976), 31, 588.

\title{
Double outlet right ventricle with L-position of the aorta, D-loop, subaortic VSD, and pulmonary stenosis
}

\author{
J. M. CAFFARENA, F. GARCIA SA NCHEZ, \\ M. CONCHA, J . M. GOMEZ-ULLA TE, J.J . PERIS, \\ R. FR I A S, E. OTERO, H. FERR ER, a nd A. MONTERO \\ Cardiovascular Surgical Service, Ciudad Sanitaria 'La Fe', Valencia, Spain
}

\begin{abstract}
Caffarena, J. M., Garcia Sanchez, F., Concha, M., Gomez-Ullate, J. M., Peris, J. J., Frias, R., Otero, E., Ferrer, H., and Montero, A. (1976). Thorax, 31, 588--594. Double outlet right ventricle with L-position of the aorta, D-loop, subaortic VSD, and pulmonary stenosis. We describe a case of double outlet right ventricle with subaortic ventricular septal defect and pulmonary stenosis treated successfully with cardiopulmonary bypass. We consider the clinical history and angiocardiographic and surgical findings of this rare anomaly.

We stress the difficulties of reconstruction of the outflow tract of the right ventricle, because of the anomalous pathway of the right coronary artery, the posterior situation of the pulmonary artery, and the abnormal anatomy present in the outflow tract of the right ventricle.
\end{abstract}

Double outlet right ventricle (DORV) is a fairly rare cardiac anomaly.

A number of papers concerning the anatomy, clinical findings, and surgical approach to the anomaly as well as descriptions of new anatomical types have been published (Kirklin, Harp, and McGoon, 1964; Hallermann et al., 1970; Gomes et al., 1971; Lev et al., 1972; Garcia Sanchez et al., 1973; Van Praagh et al., 1975).

One type presents with situs solitus, atrioventricular concordance, and L-position of the aorta associated with pulmonary stenosis and a subaortic ventricular septal defect (VSD). To our knowledge, this malformation has been successfully treated in three patients by Danielson et al. (1972), Lincoln (1972), and Kirklin (quoted by Van Praagh, 1975). We present an additional case successfully treated in our hospital.

\section{CASE REPORT}

A 12-year-old girl, born of a normal pregnancy, was investigated and diagnosed as having double outlet right ventricle in another hospital. She was cyanosed and a heart murmur was discovered at the age of 3 months. She had never had cyanotic spells or congestive heart failure. Lately she had complained of dyspnoea and palpitations on minar exertion.

On physical examination she was well developed. Generalized cyanosis was present, and clubbing of the fingers was evident. The jugulär pulse was visible at $30^{\circ}$, and the right ventriculagr impulse was palpable. On auscultation of the heart there was a systolic ejection murmur grade IV/VI at the left sternal border with maximum intensity over the pulmonary area. The second heart sound was single and very loud. The blo $\overline{\mathrm{gd}}$ pressure was $120 / 75 \mathrm{mmHg}$. The heart rate was 80 per minute. There were no signs of congestipe heart failure. The haematocrit was $55 \%$ and petspheral $\mathrm{O}_{2}$ saturation was $86 \%$.

The ECG (Fig. 1) showed sinus rhythm. T绝e axis was $150^{\circ}$. Right ventricular hypertrophy afgd possible left ventricular hypertrophy were preseth.

The chest radiograph (Fig. 2) taken on admiosion showed the apex of the heart pointing to the left and the gastric air bubble under the left dorfe of the diaphragm with a normal heart size a $\mathrm{gd}$ decreased pulmonary vascularity. 


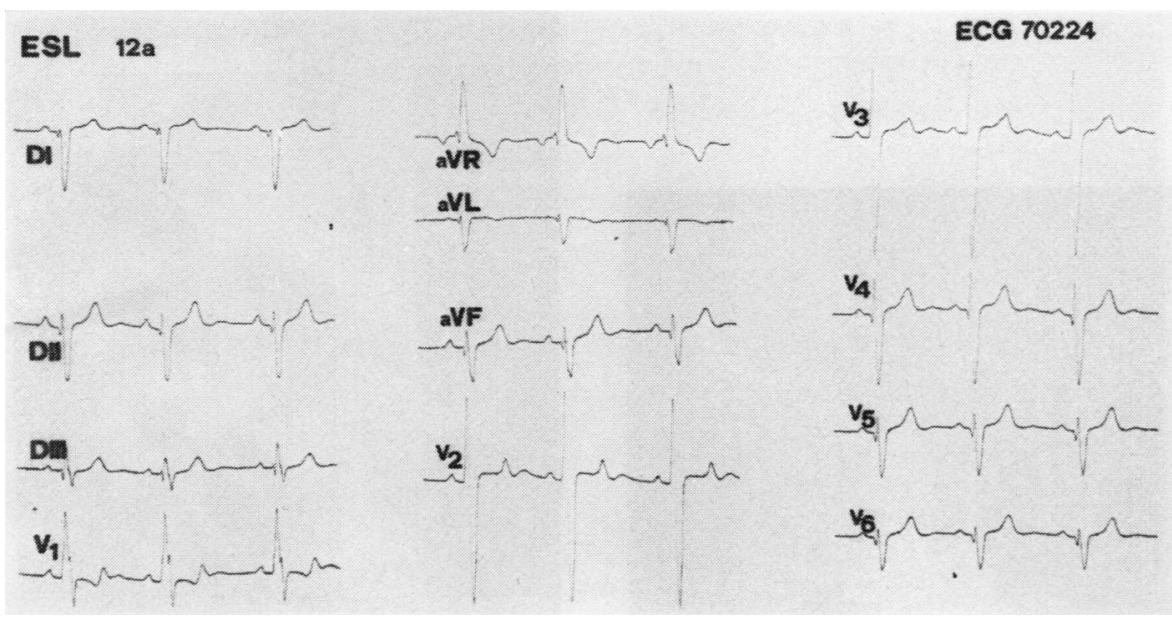

FIG. 1. Preoperative ECG: sinus rhythm 55/min, AP +60;AQRS -150. Normal auricular activity and $A-V$ conduction. Right ventricular hypertrophy.

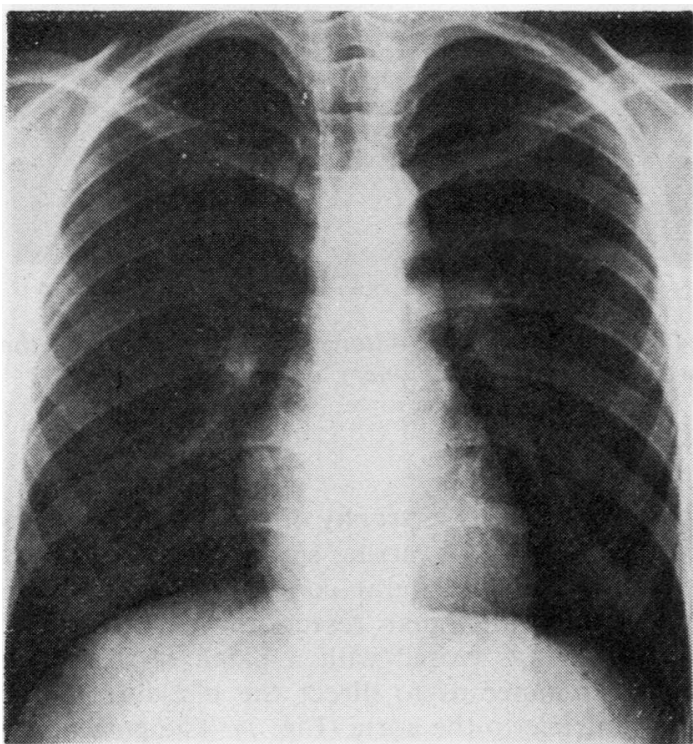

FIG. 2. Preoperative $P A$ chest radiograph. Normal heart size with prominent right and left upper heart borders and slight decrease in pulmonary vascularity. Visceral situs solitus.

Cardiac catheterization was performed on 20 February 1975; the pressures and saturations are shown in the Table. The pulmonary artery was not entered. The calculated shunts showed a left- to-right shunt $23 \%$ of the pulmonary flow and a right-to-left shunt $42 \%$ of the systemic flow.

T A B L E CARDIAC CATHETERIZATION

\begin{tabular}{|c|c|c|c|}
\hline \multicolumn{2}{|c|}{ Pressures } & \multicolumn{2}{|c|}{$\mathrm{O}_{2}$ Saturation } \\
\hline $\begin{array}{l}\text { SVC } \\
\text { IVC } \\
\text { RA } \\
\text { RV }\end{array}$ & $\begin{array}{l}\overline{8} \\
124 / 8\end{array}$ & $\begin{array}{l}71 \% \\
77 \% \\
75 \% \\
79 \%\end{array}$ & $\begin{array}{ll}\text { R-L shunt } & 23 \% \\
\text { L-R shunt } & 42 \% \\
\text { QP/QS } & 0.7\end{array}$ \\
\hline $\begin{array}{l}\text { PA } \\
\text { LV }\end{array}$ & $\begin{array}{l}\text { not entered } \\
124 / 6 \\
0\end{array}$ & $89 \%$ & \\
\hline Ao & $124 / 80$ & $86 \%$ & \\
\hline
\end{tabular}

SVC = superior vena cava IVC $=$ inferior vena cava RA $=$ righ atrium; $\mathbf{R V}=$ right ventricle; $\mathbf{P A}=$ pulmonary artery; $\mathbf{L V}=$ left ventricle; $A 0=$ aorta; $R L=$ right-to-left shunt; $L R=$ left-to-right shunt; $\mathbf{Q R} / \mathrm{QS}=$ pulmonary to systemic flow ratio.

Selective angiograms were performed in the right and left ventricles, showing (Fig. 3a, b) that the aorta and pulmonary arteries arose from the right ventricle. The aorta was (in L-position) to the left of the pulmonary artery. The left ventriculogram (Fig. 4) showed a posterior left ventricle and a large VSD in a subaortic position. There was a mixed valvar and subvalvar pulmonary stenosis and the course of the coronary arteries was not well visualized.

The final diagnosis was double outlet right ventricle with situs solitus, D-Loop, and L-position of the aorta associated with a large subaortic VSD and pulmonary stenosis. 


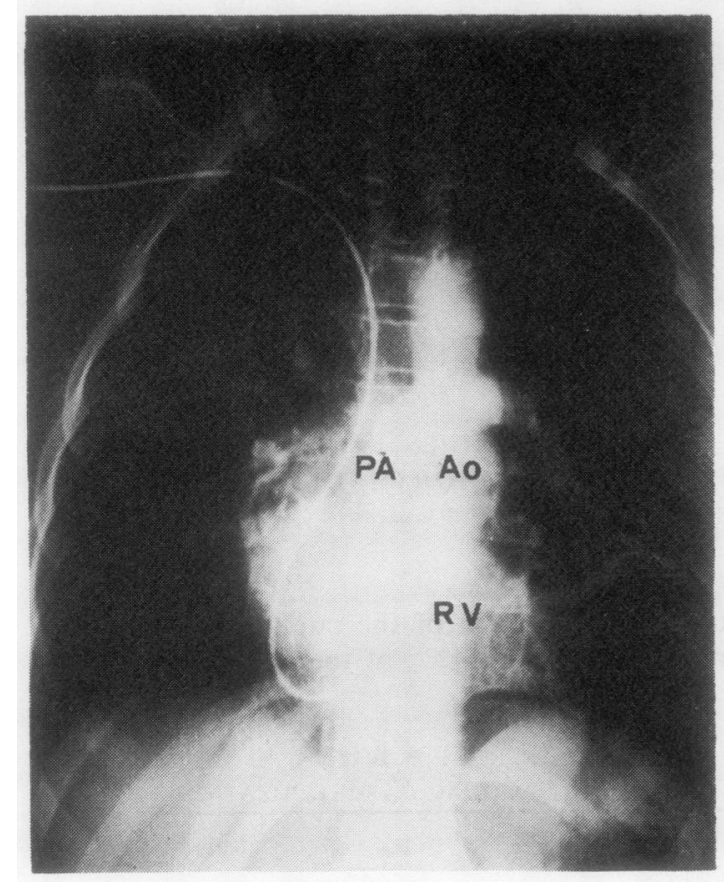

(a)

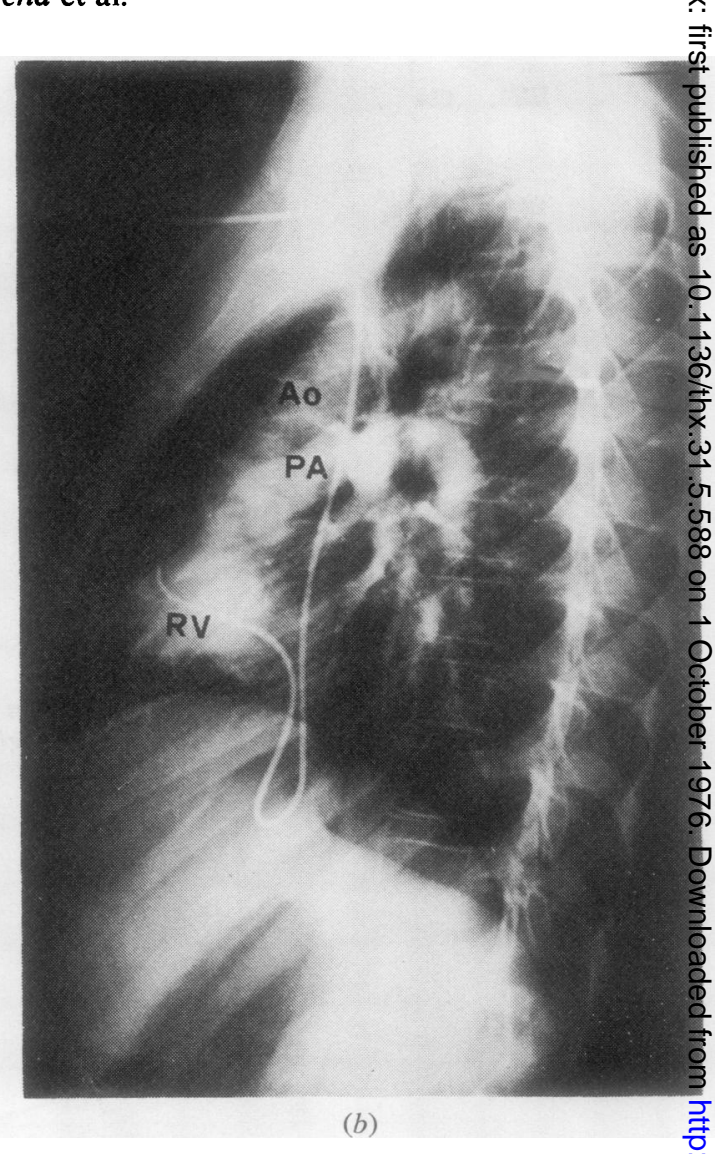

FIG. 3(a,b) PA and lateral right ventricular angiocardiograms show a simultaneous opacification of the aorta and pulmonary arteries; the aorta is anterior and to the left of the pulmonary artery. Ao=aorta; $P A \overline{\vec{\sigma}}$ pulmonary artery; $R V=$ right ventricle.

Total correction was performed in February 1975 through a median sternotomy using cardiopulmonary bypass. General hypothermia to $24^{\circ} \mathrm{C}$ was employed with intermittent aortic crossclamping. The total bypass time was 150 minutes with four periods of $21,22,22$, and 8 minutes of myocardial ischaemia.

The external appearance of the heart (Fig. 5) showed the aorta to be situated to the left of the pulmonary artery. The diameter ratio of the two vessels was 3 to 1 . There was a thrill over the pulmonary artery; the right coronary artery crossed the outflow tract of the right ventricle near the origin on the pulmonary artery.

Through an oblique right ventriculotomy (Fig. 6) a VSD was seen high in the septum measuring $2 \times .2 .5 \mathrm{~cm}$, with its posteroinferior margin next to the anterior and septal leaflets of the tricuspid valve. Marked hypertrophy of the septal and paisetal bands of the crista supraventricularis was evident, and a bilateral conus was present. An extensive infundibular resection was performed. The VSD was closed with a patch of Teflon such a manner as to direct the blood from the left ventricle to the aorta (Fig. 7). The pulmonary artery was opened vertically to show a markd valvar stenosis. An outflow patch was used widen the pulmonary valve ring and the origin of the outflow tract of the right ventricle as far down as the abnormal right coronary artery. The right ventriculotomy was closed and the heart started to beat spontaneously when the temperature reached $30^{\circ} \mathrm{C}$. Pressures taken after coming बff bypass showed a right ventricular pressure $\& \mathrm{f}$ $70 \mathrm{mmHg}$ and a left ventricular pressure $\underset{8}{\mathrm{~g}}$ $90 \mathrm{mmHg}$. 


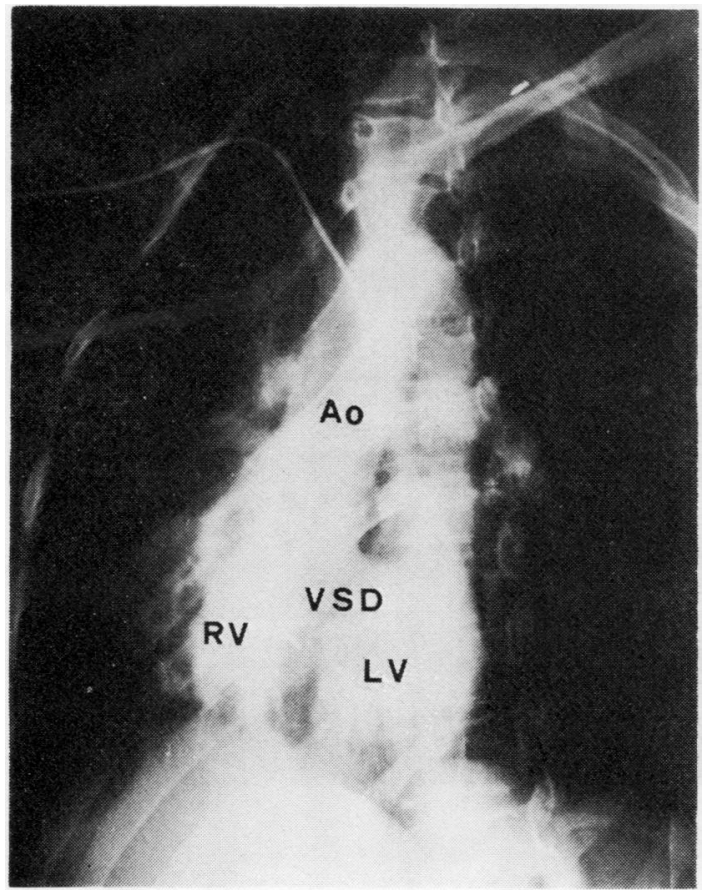

FIG. 4. Left ventricular angiocardiogram shows the posterior situation of the left ventricle, a high VSD with opacification of the right ventricle, and both great arteries arising from the $R V$. Ao=aorta; $V S D=$ ventricular septal defect; $R V=$ right ventricle; $L W=$ left ventricle.

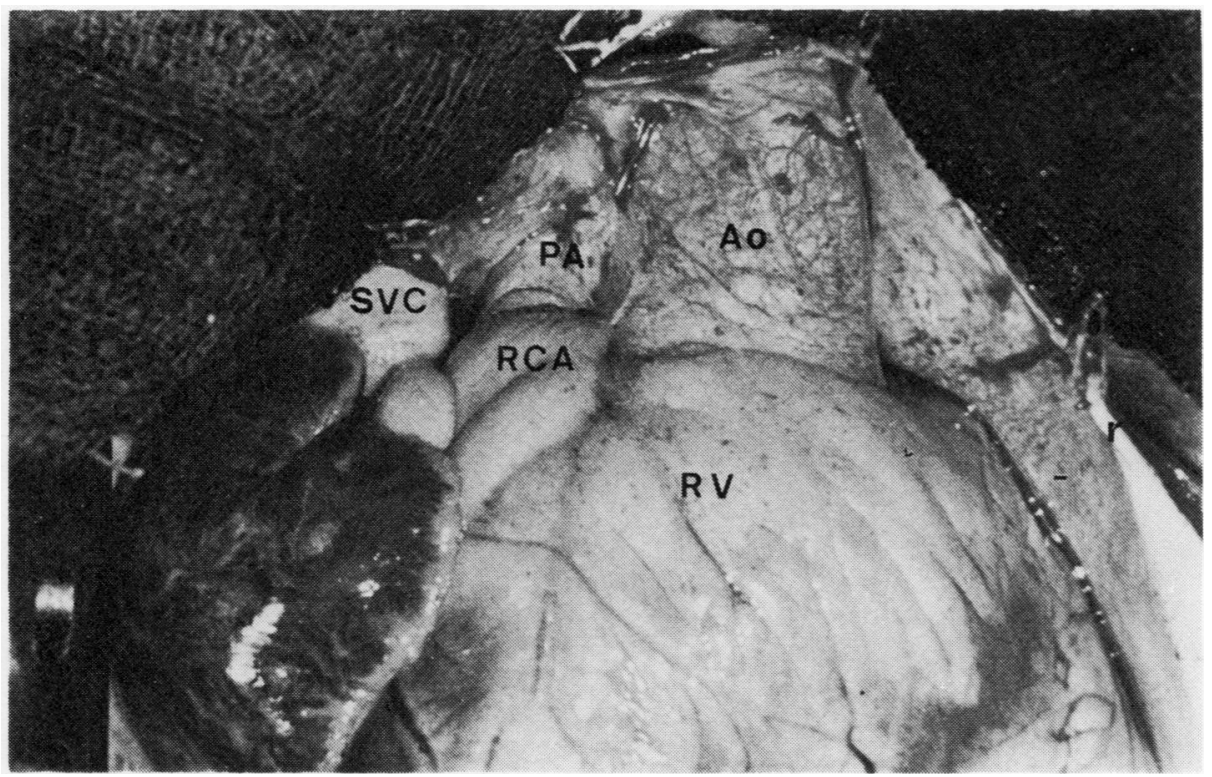

FIG. 5. Intraoperative photograph shows the external appearance of the heart. The great arteries arise side by side from the right ventricle. The pulmonary artery diameter is onethird that of the aorta. The aorta is to the left of the pulmonary artery. The right coronary artery crosses the $R V$ outflow tract. $A o=$ aorta; $P A=$ pulmonary artery; $R V=$ right ventricle; $R C A=$ right coronary artery; $S V C=$ superior vena cava. 


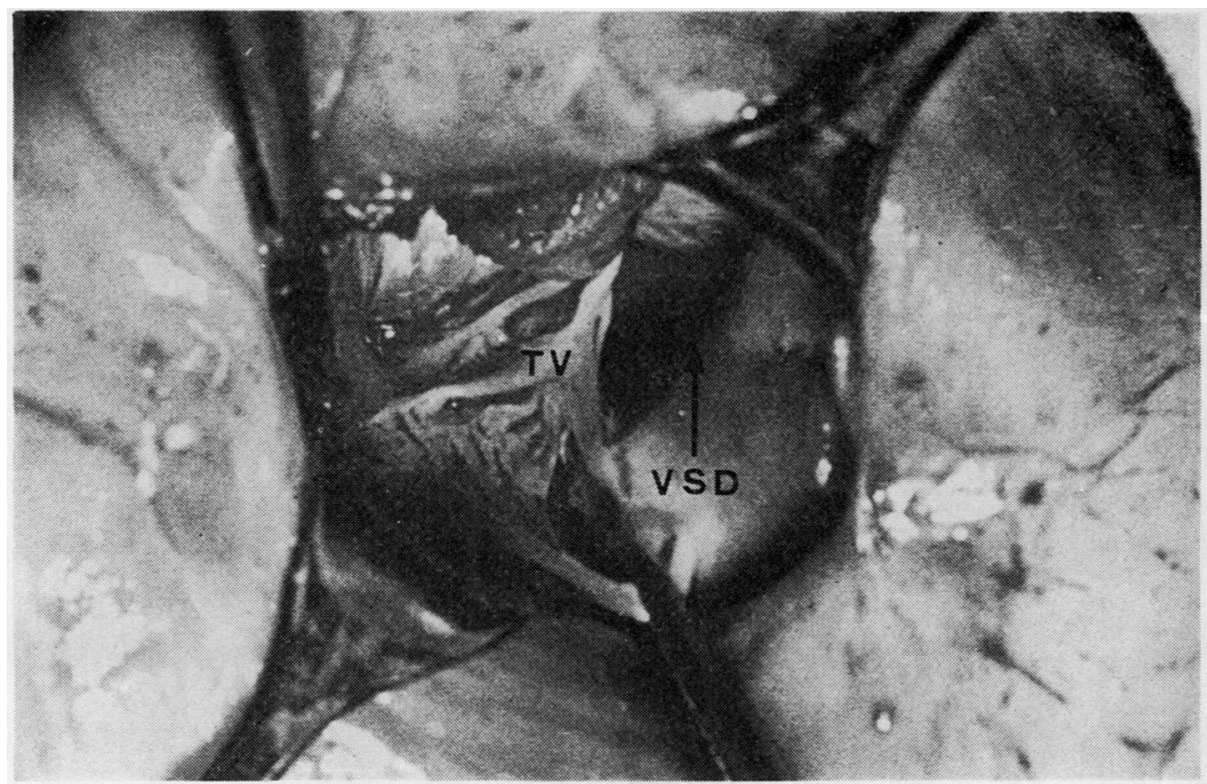

(a)

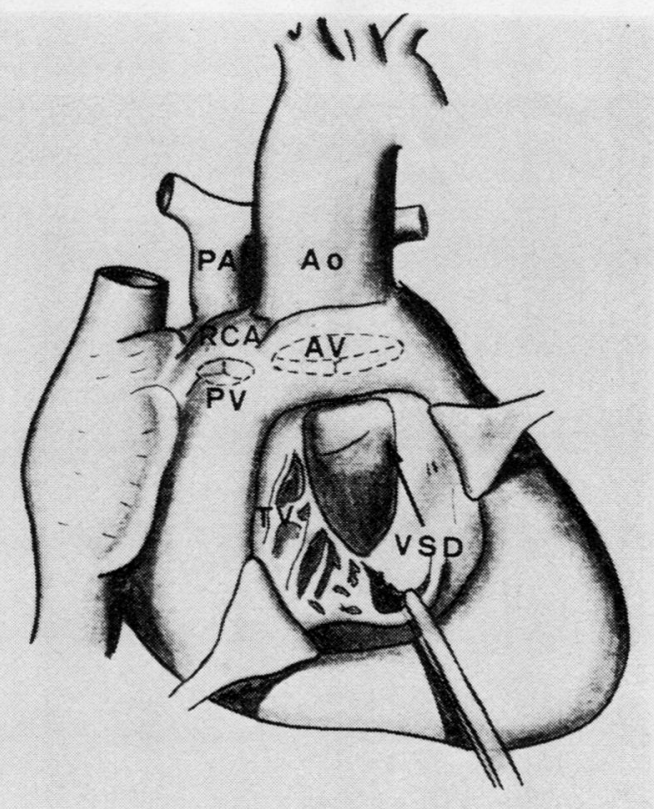

(b)

FIG. 6. Intraoperative photograph shows the anatomy of the right ventricle through the ventriculotomy. There is a large subaortic VSD. It also shows the relation and size of the pulmonary and aortic valves. $A o=a o r t a ; P A=$ pulmonary artery; $A V=a o r t i c$ valve; $P V=$ pulmonary valve; $T V=$ tricuspid valve; $V S D=v e n t r i c u l a r$ septal defect; $R C A=$ right coronary artery. 


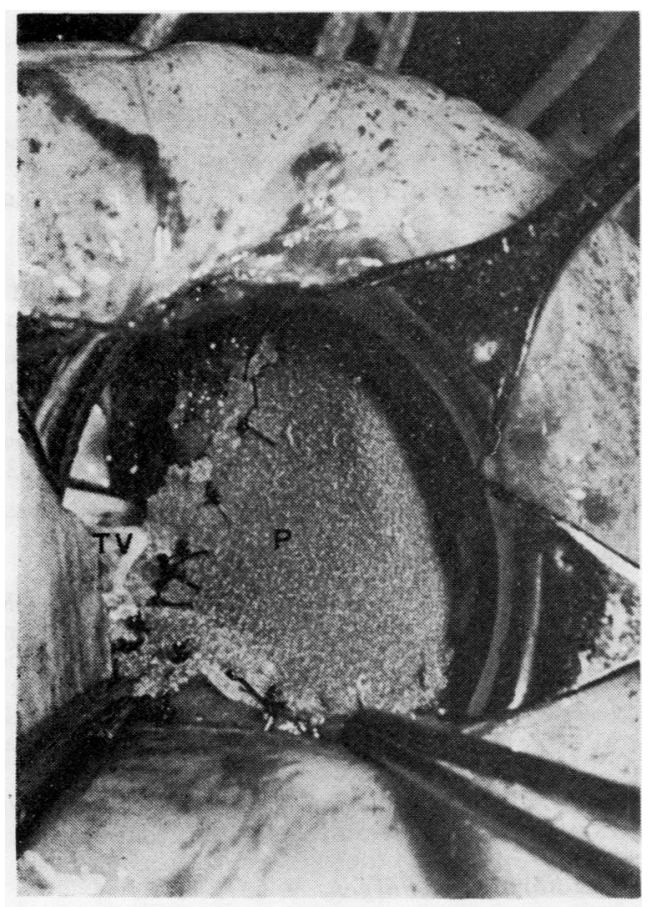

(a)

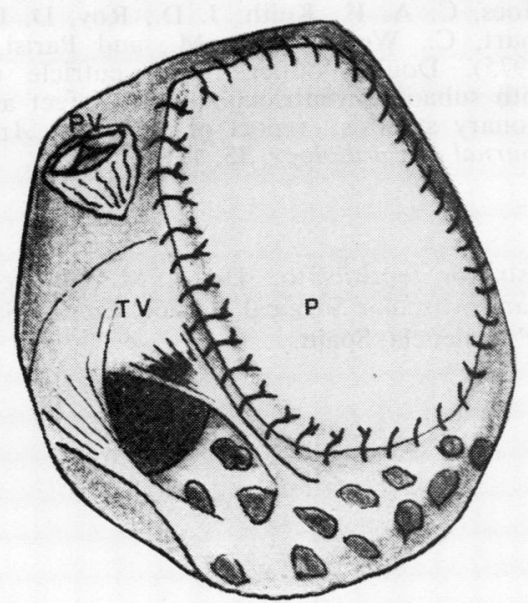

(b)

FIG. 7. Intraoperative photograph shows the subpulmonary muscle resection as well as the VSD closed with a Teflon patch. $T V=$ tricuspid valve; $P=$ Teflon patch; $P V=$ pulmonary valve.

The pulmonary artery pressure was $40 \mathrm{mmHg}$. In spite of this gradient the cannulae were removed and the chest was closed after bleeding points had been controlled.
The postoperative course was uneventful and the patient was discharged from hospital 20 days after operation taking digoxin; her general condition was very much improved and her cyanosis had disappeared.

At the present time, five months after the operation, she continues to do well and is awaiting cardiac catheterization to assess her haemodynamic state.

\section{DISCUSSION}

Surgical correction of double outlet right ventricle was described by McGoon (1961), Kirklin et al. (1964), Gomes et al. (1971), and Pacifico, Kirklin, and Bergeron (1973).

More complex forms of DORV have recently been treated surgically with success (Patrick and McGoon, 1968; Van Praagh et al., 1975; Hightower et al., 1969; Danielson et al., 1972; Lincoln, 1972).

The case we present is similar to those described by Danielson et al. (1972) and Lincoln (1972) which were the first two cases treated with the aid of cardiopulmonary bypass. Both authors described an intraventricular tunnel to close the VSD in such a manner as to direct the blood from the left ventricle to the aorta. In Lincoln's case an outflow patch was needed and was extended beneath an abnormal right coronary artery.

More recently, Kirklin (quoted by Van Praagh, 1975) has treated another case in which he had to reconstruct the outflow tract of the right ventricle with an external conduit. To our knowledge, the case that we present here is the fourth successfully treated. In our case a pulmonary gradient of $30 \mathrm{mmHg}$ remained in spite of the patch used for reconstruction of the outflow tract of the right ventricle. In the case reported by Danielson et al. (1972) a similar gradient remained without using a patch across the outflow tract.

It is evident that the closure of the VSD to redirect the flow to its normal pathway is not difficult. The problem in dealing with the outflow tract of the right ventricle arises. This is due to the anomalous right coronary artery crossing the outflow tract of the right ventricle and to the degree of pulmonary hypoplasia. As Van Praagh et al. (1975) have stated, if the pulmonary stenosis is not severe, it might be possible to deal with it by infundibular resection and pulmonary valvotomy; sometimes a patch is needed. On the other hand, in those cases where the right ventricular hypoplasia is marked, a valved external conduit should be used to relieve the obstruction. 
From the clinical point of view the symptoms and signs were similar to those of Fallot's tetralogy; the definitive diagnosis is made by cardiac catheterization and ventricular angiograms showing the exact anatomy of the condition. We think selective coronary arteriography may be helpful to show the exact pathway of the right coronary artery.

\section{REFERENCES}

Danielson, G. K., Ritter, D. G., Coleman, H. N., and DuShane, J. W. (1972). Successful repair of double-outlet right ventricle with transposition of the great arteries (aorta anterior and to the left), pulmonary stenosis, and subaortic ventricular septal defect. Journal of Thoracic and Cardiovascular Surgery, 63, 741.

Garcia Sanchez, F., Concha Ruiz, M., Frías Martín, R., Gomez-Uliate, J. M., Peris Pedro, J. J., Cebolla, R., Algarra, F., and Caffarena Raggio, J. M. (1973). Doble salida del ventriculo derecho: importancia de la localización y tamaño de la communicación interventricular en la técnica quirúrgica. Revista Espanola de Cardiologia, 26, 51.

Gomes, M. M. R., Weidman, W. H., McGoon, D. C., and Danielson, G. K. (1971). Double-outlet right ventricle with pulmonic stenosis: surgical considerations and results of operation. Circulation, 43, 889.

Hallermann, F. J., Kincaid, O. W., Ritter, D. G., Ongley, P. A., and Titus, J. L. (1970). Angiocardiographic and anatomic findings in origin of both great arteries from the right ventricle. American Journal of Roentgenology, 109, 51.

Hightower, B. M., Barcia, A., Bergeron, L. M., Jr., and Kirklin, J. W. (1969). Double-outlet right ventricle with transposed great arteries and sub-pulmonary ventricular septal defect: the
Taussing-Bing malformation. Circulation, 39, Supplement I, 207.

Kirklin, J. W., Harp, R. A., and McGoon, D. C. 흘 (1964). Surgical treatment of origin of both vessels from right ventricle, including cases of $\stackrel{\square}{Q}$ pulmonary stenosis. Journal of Thoracic and@ Cardiovascular Surgery, 48, 1026.

Lev, M., Bharati, S., Meng, L., Liberthson, R. R., $\overrightarrow{0}$ Paul, M. H., and Idriss, F. (1972). A concept of double-outlet right ventricle. Journal of Thoracice and Cardiovascular Surgery, 64, 271.

Lincoln, C. (1972). Total correction of D-Loop $\vec{x}$ double-outlet right ventricle with bilateral conus, $\omega$ L-transposition, and pulmonic stenosis. Journal of Thoracic and Cardiovascular Surgery, 64, 435. or

McGoon, D. C. (1961). Origin of both great vesselso from the right ventricle. Surgical Clinics of North America, 41, 1113.

Pacifico, A. D., Kirklin, J. W., and Bergeron, L. M. $\overrightarrow{0}$ Jr. (1973). Complex congenital malformations: surgical treatment of double-outlet right ventricle and double-outlet left ventricle. In Advances in Cardiovascular Surgery, edited by J. W. Kirklin, pp. 57-76. Grune and Stratton, New York ande London.

Patrick, D. L. and McGoon, D. C. (1968). An operation for double-outlet right ventricle wito transposition of the great arteries. Journal o Cardiovascular Surgery, 9, 537.

Van Praagh, R., Pérez-Trevino, C., Reynolds, J. L ٌ Moes, C. A. F., Keith, J. D., Roy, D. L., Beh court, C., Weinberg, P. M., and Parisi, L. P. (1975). Double outlet right ventricle (S,D,,$\vec{D}$ with subaortic ventricular septal defect and puB monary stenosis: report of six cases. Americaz Journal of Cardiology, 35, 42.

Requests for reprints to: Dr. J. M. Gcmez-Ullatê The Cardiovascular Surgical Service, Ciudad Sanitar 'La Fe', Valencia, Spain. 